\title{
Experimental analysis and WallDYN simulations of the global nitrogen migration in ASDEX Upgrade L-mode discharges
}

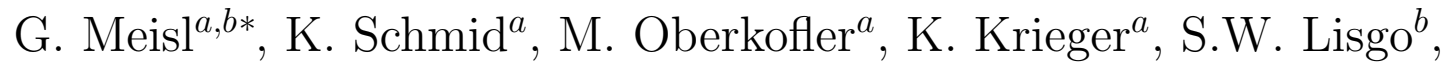 \\ L. Aho-Mantila ${ }^{c}$, F. Reimold ${ }^{a}$, T. Lunt ${ }^{a}$ and ASDEX Upgrade Team \\ ${ }^{a}$ Max-Planck-Institut für Plasmaphysik, Boltzmannstraße 2, 85748 Garching, Germany \\ ${ }^{b}$ Physik-Department E28, Technische Universität München, 85747 Garching, Germany \\ ${ }^{c}$ ITER Organization, FST, Route de Vinon, CS 90 046, 13067 Saint Paul Lez Durance Cedex, France \\ ${ }^{d}$ VTT Technical Research Centre of Finland, P.O.Box 1000, FI-02044 VTT, Finland
}

December 14, 2015

\begin{abstract}
This work presents ASDEX Upgrade experiments, where the nitrogen deposition, reerosion on divertor manipulator samples and the effect of its transport through the plasma were studied. These results are compared to WallDYN-DIVIMP simulations based on SOLPS plasma backgrounds and employing an improved WallDYN model, which includes the effusion of nitrogen from saturated surfaces. On one hand, this allows to benchmark the WallDYN code and the new saturation model with a comprehensive data set, on the other hand the simulations help in the interpretation of the experimental results. Both, experimental results and simulations, show that the $\mathrm{N}$ content in the region of the outer

*gmeisl@ipp.mpg.de
\end{abstract}


strike line reaches its steady-state value within one discharge. The simulations also reproduce the experimentally observed nitrogen content in samples exposed to $\mathrm{N}_{2}$-seeded discharges. With respect to the boron deposition, the nitrogen deposition in a non-seeded discharge and the re-erosion of nitrogen discrepancies to the WallDYN-DIVIMP simulations are observed. Based on SDTrimSP simulations, these are attributed to the missing depth resolution of the WallDYN surface model. A detailed comparison of spectroscopic measurements to WallDYN simulations, based on a novel synthetic spectroscopy diagnostic for WallDYN, shows that the nitrogen fluxes in the plasma are well described by the simulations. From a comparison of several WallDYN-DIVIMP simulations employing customized onion-skin model plasma backgrounds the physical processes controlling the nitrogen concentration in the core plasma and the applicability of onion-skin model plasma backgrounds are discussed. From these simulations the private flux zone with the gas valve, the outer baffle and the high field side main wall are identified as the main sources for the nitrogen content of the core plasma.

PACS: 52.25.Vy, 52.40.Hf, 52.65.-y, 79.20.-m, 52.55.Fa

\section{Introduction}

Experiments in several tokamaks have demonstrated that the addition of small amounts of nitrogen to the hydrogen plasma can effectively reduce the power load on the divertor targets in tokamaks with a low amount of intrinsic impurities like C [1, 2, 3]. However, in contrast to hydrogen and noble gases, $\mathrm{N}$ chemically interacts with tungsten surfaces. That means, nitrogen from the plasma is stored in tungsten wall surfaces and can be released back into the plasma under particle or thermal loads [4, 5]. A peculiarity of $\mathrm{N}$ compared to solid elements such as carbon or metals is that the plasma facing surfaces have a limited $\mathrm{N}$ storage capacity and excess $\mathrm{N}$ is reemitted from the surfaces. This behavior results in a largely homogeneous distribution of $\mathrm{N}$ on the AUG surfaces [6]. As the nitrogen deposition can modify the $\mathrm{W}$ erosion or the hydrogen retention [4, 7], a quantitative prediction of $\mathrm{N}$ fluxes and deposition is desirable. Furthermore, self-consistent models of nitrogen wall retention and fluxes in the plasma are helpful in the 
development of algorithms to control the power load via the nitrogen puff [8].

This work presents results from AUG experiments on the nitrogen transport and deposition based on well diagnosed L-mode discharges and employing a comprehensive set of diagnostics. The combination of spectroscopic measurements with measurements of the $\mathrm{N}$ implantation into samples exposed on the divertor manipulator, allows to study both the $\mathrm{N}$ fluxes and the $\mathrm{N}$ divertor deposition. This comprehensive set of experimental data is employed to benchmark WallDYN [9, 10] simulations based on plasma backgrounds generated with different models. The WallDYN simulations are then employed to study the $\mathrm{N}$ transport in the plasma. First results from this work have shown, that WallDYN simulations quantitatively reproduce the nitrogen areal density on AUG divertor surfaces and the long term nitrogen retention [11].

Besides the chemical interaction of $\mathrm{N}$ with $\mathrm{W}, \mathrm{N}$ in a fusion plasma also reacts with hydrogenic species to form ammonia [12, 13, 14]. This process may contribute to the retention of $\mathrm{N}$ in the vacuum vessel, as ammonia desorbs very slowly from surfaces and may reach remote parts of the vacuum vessel. However, the areal density resulting from adsorption of $\mathrm{N}$ containing molecules should be rather low As the $\mathrm{N}$ areal density on plasma wetted surfaces should then be dominated by $\mathrm{N}$ implantation $\mathrm{b}$ the problem of ammonia formation and retention will not be discussed further in this work. Nevertheless, the improved understanding of the $\mathrm{N}$ implantation into $\mathrm{W}$ is also considered to be a valuable input for the development of a better understanding of the ammonia formation.

\section{Methods}

\subsection{Discharge setup}

The chosen plasma scenario was a well diagnosed L-mode discharge. The L-mode scenario was chosen to avoid the complications arising due to the onset of ELMs. The discharge had a

\footnotetext{
a The $\mathrm{N}$ areal density resulting from the chemisorption of $\mathrm{N}_{2}$ on $\mathrm{W}$ surfaces is of the order of $10^{19} \mathrm{~N} / \mathrm{m}^{2}[15]$

${ }^{\mathrm{b}} \mathrm{By}$ ion implantation a few $10^{21} \mathrm{~N}$ atoms can be stored in the main wall, up to 100 times more than contained in the plasma [11]
} 
plasma current of $1 \mathrm{MA}, 450 \mathrm{~kW}$ of ECRH heating and a line averaged core density of about $4 \cdot 10^{19} \mathrm{~m}^{-3}$. For these discharge parameters, SOLPS plasma backgrounds with the best available reproduction of the plasma parameters in the outer divertor region are used [16, 17].

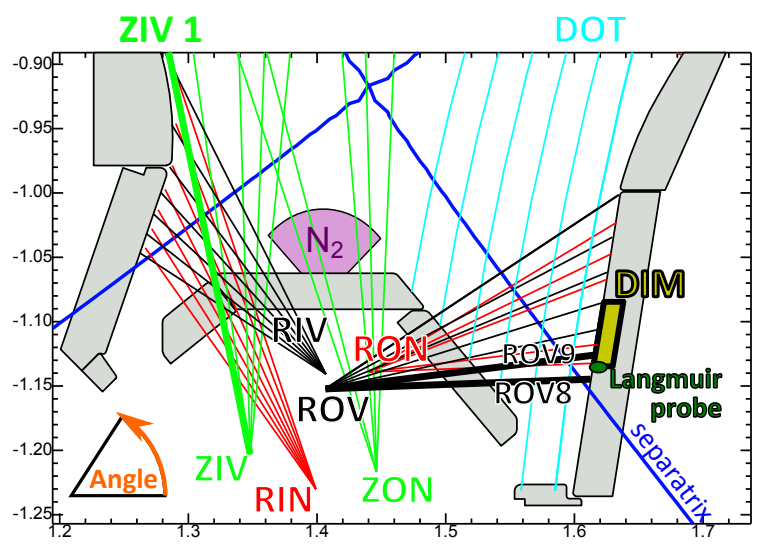

Figure 1: Positions of the $N_{2}$ valve and the diagnostics used in this work, especially the divertor manipulator (DIM) and spectroscopic lines of sight. All lines of sight are compared in Fig. 11, where their angle with the horizontal, as indicated in the lower left, is used as x-axis. For the ZIV1 and ROV8/9 lines of sights, timetraces are shown in this work.

The experiments presented in this work were performed on two different days in the discharges \#29695 to \#29698 and \#29730 to \#29732. In the N-seeded discharges an average N seeding rate of $2.9 \cdot 10^{20} \mathrm{~N} / \mathrm{s}$ was applied from $1.4 \mathrm{~s}$ to $2.4 \mathrm{~s}$ and from $2.9 \mathrm{~s}$ to the end of the discharge. Valves with 8 toroidally distributed outlets in the roof baffle of the divertor were chosen for the puff to maintain the toroidal symmetry. The puff location, the position of the divertor manipulator (DIM) and further diagnostics is shown in Fig. 1. As a minimum flux is required to open the valve, the puff was modulated as shown in Fig. 2 (10 ms on, $30 \mathrm{~ms}$ off). The valve is connected to the outlets in the roof baffle via a tube of $3 \mathrm{~m}$ length, so the original modulation in the puff is smoothed out by the transport through this tube.

In theses discharges samples were exposed on the DIM to different combinations of Nseeded and non-seeded discharges. The employed samples consisted of a $2 \mu \mathrm{m}$ thick $\mathrm{W}$ layer on a fine grain graphite substrate. The $\mathrm{W}$ layers were produced by the same combined magnetron sputtering and ion implantation process as the main AUG wall tiles [18]. An overview over the allocation of the samples exposed in the DIM to the different discharges, the phases with $\mathrm{N}_{2}$ 
puff and spectroscopic measurements is shown in Fig. 3 .

- A sample was exposed to discharge \#29695, which was a reference discharge without $\mathrm{N}_{2}$ puff.

- Samples were exposed to a single N-seeded discharge in \#29696 and on the second day for comparison in \#29730. A sample was exposed to two subsequent N-seeded discharge \#29731 and \#29732.

- A sample was loaded with nitrogen in the N-seeded discharge \#29697 and then exposed to \#29698, which was without $\mathrm{N}_{2}$ puff, to study the re-erosion of nitrogen.

During the discharges $\mathrm{N}$ accumulates in the vessel, so the core $\mathrm{N}$ concentration (black stars in Fig. 3) and the emission measured with the line of sight ZIV1 (magenta curve) rise from \#29696 to \#29697 and from \#29730 to \#29731. The N content of the plasma in \#29698 is notably higher than in the previous non-seeded discharge \#29695. Spectroscopic measurements are further discussed in section 4 .

The applied $\mathrm{N}_{2}$ puff is rather weak in comparison to the value of $3 \cdot 10^{21} \mathrm{~s}^{-1}$ suggested in Ref. [19] and the rates used for power load control, which are above $10^{21} \mathrm{~N} / \mathrm{s}$ [8]. Nevertheless, as can can be seen in Fig. 2, the electron temperature measured by the Langmuir probe shown in Fig. 1] was not constant over the flattop phase but drops to lower values when the $\mathrm{N}_{2}$ puff is switched on. This drop marks a transition into a detachment state with divertor plasma oscillations as described in Ref. [20]. During the non-seeded phase in the middle of the discharge the plasma nitrogen content drops and the divertor plasma changes back to its original (higher $T_{e}$ ) state. As can be seen from the spectroscopic measurement along the ROV9 line of sight in Fig. 3 (dark red line), the variation in the divertor plasma conditions and the plasma oscillations affect the $\mathrm{N}$ line emission and complicate the interpretation of the observed spectroscopic intensity variations. 


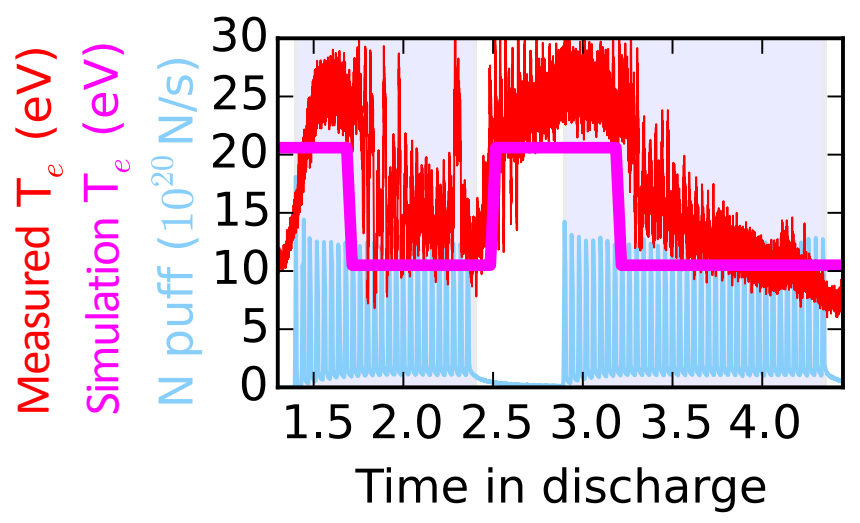

Figure 2: $N$ puff (lower curve), $T_{e}$ employed in the simulations (magenta line) and $T_{e}$ from a Langmuir probe close to the outer strike line during discharge \#29696 (red curve). In the N-seeded phases the electron temperature in the outer divertor drops due to the increased level of radiation emitted from the plasma.

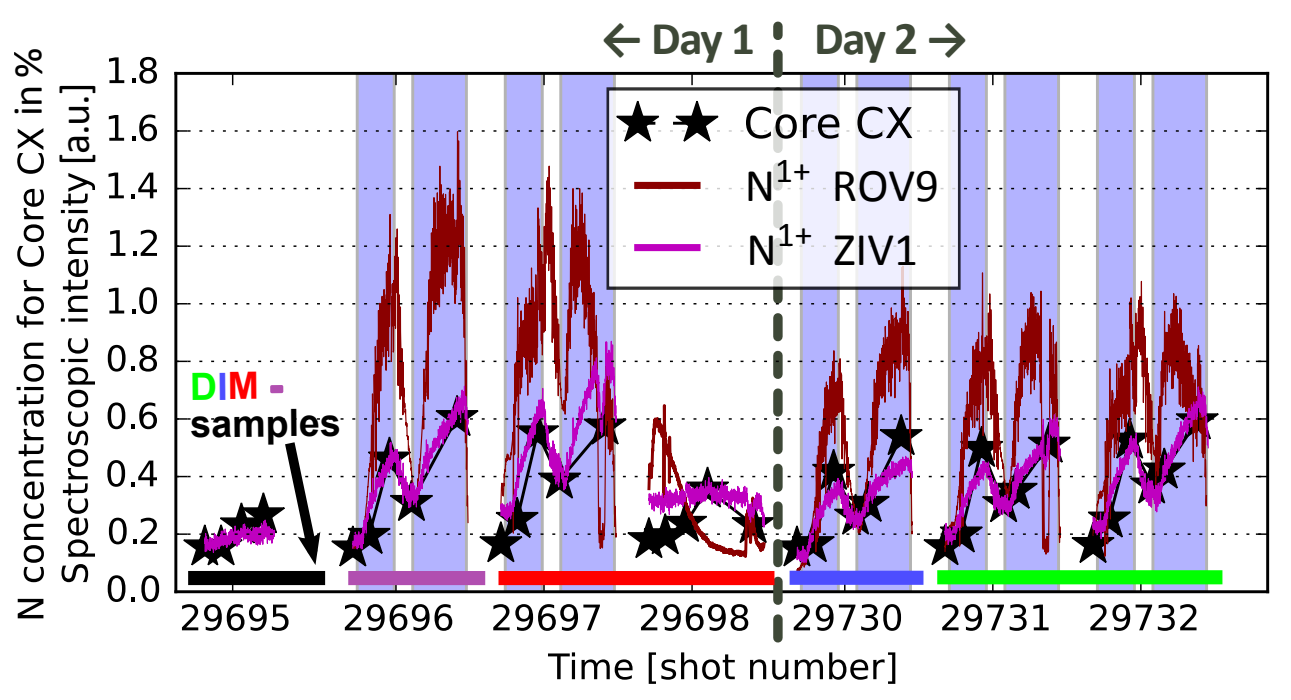

Figure 3: Overview of sample allocation to the different discharges and spectroscopic $N$ measurements. The charge exchange recombination spectroscopy (CXRS) measures the absolute $N$ concentration in the core plasma. The measurements from passive spectroscopy were scaled to match the core $N$ concentration in the beginning of \#29696, the same scaling factor was applied to all discharges. The lines of sight in the divertor are shown in Fig. 1. The $N$ content rises during the $N_{2}$ puff (indicated by the blue background) and latency increases the long-term $N$ content after the puffs. 


\subsection{Spectroscopy and Fast Cameras}

With their better temporal and spatial resolution, spectroscopic measurements offer complementary information to the sample analysis results presented in Ref. [5]. The geometric lines of sight used for the passive divertor spectroscopy are shown in Fig. 1. Here it should be noted that with the metallic walls spectroscopic measurements may be affected by reflected emission originating from other regions in the plasma. To minimize contributions from reflected light, the $R O V$ and $R I V$ lines of sight are aligned to view into gaps between two wall tiles. However, with this alignment also the particle fluxes from the surfaces may be underestimated because the near-surface contribution is missing. Emission at the following wavelength was analyzed for the present work:

- The emission from neutral $\mathrm{N}$ atoms around $746.8 \mathrm{~nm}$. A calibration of the spectrometer for the low field side lines of sight (RON, ROV) was only available until $726 \mathrm{~nm}$, so the calibration had to be extrapolated from this wavelength and is associated with some uncertainty. For the high field side lines of sight (RIN) no calibration was available for this wavelength, so a (common) estimated calibration factor was used for these lines of sight.

- The emission from $\mathrm{N}^{1+}$ around $500 \mathrm{~nm}$ was measured with calibrated spectrometers.

- Fast cameras with filters were used to observe the emission around 502 and $747 \mathrm{~nm}$.

The S/XB method, which is commonly used to convert the line integrated measurements of emitted photons to particles fluxes, requires that the selected ion species are spatially well localized [21]. Unfortunately, our impurity transport simulations suggest that for the present plasma conditions, with a rather cold plasma especially in the inner divertor and private flux region, this requirement is not fulfilled. For this reason we employ an alternative approach, where first the number of emitted photons per volume is calculated from the simulated $\mathrm{N}$ ion distribution and ADAS [22] data, with the $T_{e}$ and $n_{e}$ data taken from the plasma background 
(the result from such a calculation for neutral $\mathrm{N}$ atoms is shown in Fig. 12a). Then we calculate the spectroscopic signals (Photons $/ \mathrm{m}^{2} / \mathrm{s} / \mathrm{sr}$ ) by line integrations along the geometric lines of sight. This allows a quantitative comparison of the simulated impurity fluxes to the spectroscopic measurements for all available lines of sight.

A spectroscopic technique that allows for spatially localized measurements of the impurity concentration is the charge exchange recombination spectroscopy (CXRS) 23]. The core nitrogen concentration in the studied discharges was homogeneous, so only radially averaged concentrations are given. The CXRS system relies on the neutral atoms injected by the NBI heating system. However, the applied heating power had to be kept below the H-mode threshold. Therefore, the NBI could only be activated shortly for a few selected points in time and the CXRS measurements are only available at these particular times.

\subsection{Sample analysis}

On the samples exposed on the divertor manipulator of AUG the nitrogen and boron areal densities were measured by nuclear reaction analysis (NRA). The ${ }^{14} \mathrm{~N}\left({ }^{4} \mathrm{He},{ }^{1} \mathrm{H}\right){ }^{17} \mathrm{O}$ reaction at a ${ }^{4} \mathrm{He}$ energy of $4.94 \mathrm{MeV}$ was used to optimize the signal from nuclear reactions with $\mathrm{N}$ over the background. The number of counts was converted into an areal density by comparison to the signals generated by $\mathrm{B}$ and $\mathrm{CN}_{x}$ layers with known $\mathrm{N}$ areal density. For the NRA measurements of $\mathrm{N}$, all results are based on at least 100 counts, corresponding to a statistical error of $\leq 10 \%$. The cross section for the nuclear reaction with boron is smaller than that between ${ }^{4} \mathrm{He}$ and ${ }^{14} \mathrm{~N}$. For this reason there is some uncertainty in the measurements of low boron areal densities. For the measurement of the $\mathrm{N}$ areal density it has to be noted that nitrogen is adsorbed on every surface which has been carried through air. This should result in a background areal density of the order of $10^{19} \mathrm{~N} / \mathrm{m}^{2}$ [15]. 


\subsection{WallDYN}

Migration is a multiscale problem and therefore most of the available models either simulate only the impurity transport in the plasma (assuming a fixed wall composition) or the evolution of the material surfaces on the microscopic scale (assuming constant impurity fluxes). WallDYN [9, 10, 14] is a global impurity migration code which simulates self-consistently the time evolution of the impurity fluxes and the surface composition. This allows to interpret the various measurements within one self-consistent model incorporating the erosion and deposition processes as well as the transport of impurities through the plasma. WallDYN can either be used to predict erosion and migration in future fusion experiments like ITER or to support the interpretation of available experimental measurements. As WallDYN is a novel tool in the simulation of impurity migration, comparisons with experimental measurements are also required for benchmarking. The aim of the present work is therefor not only to support the interpretation of the experimental results, but also to check the WallDYN predictions with this experimental data.

The WallDYN model is illustrated in Fig. 4. For the numerical simulation the continuous wall configuration is discretized into wall tiles. Each wall tile consists of a thin reaction zone at the surface and an infinite bulk with a fixed composition. The composition of the reaction zone is modified by the incoming impurities and is used to calculate the erosion flux from this tile. The total areal density of the reaction zone, chosen to match a typical implantation depth of $4 \mathrm{~nm}$, is kept constant by a flux of matter from or to the bulk.

The transport of the impurities from one wall tile to another is described by the so called re-distribution matrix. This matrix is a parametrization of DIVIMP simulations [24, 25]. The DIVIMP simulations and the employed plasma backgrounds are described below. For a given source location the charge state resolved re-distribution matrix contains the fraction of particles which are transported to each of the wall tiles in a given charge state. An example for a simple, charge state integrated re-distribution matrix is contained in Fig. 4, a full charge state integrated matrix is given in Fig. 16 . 


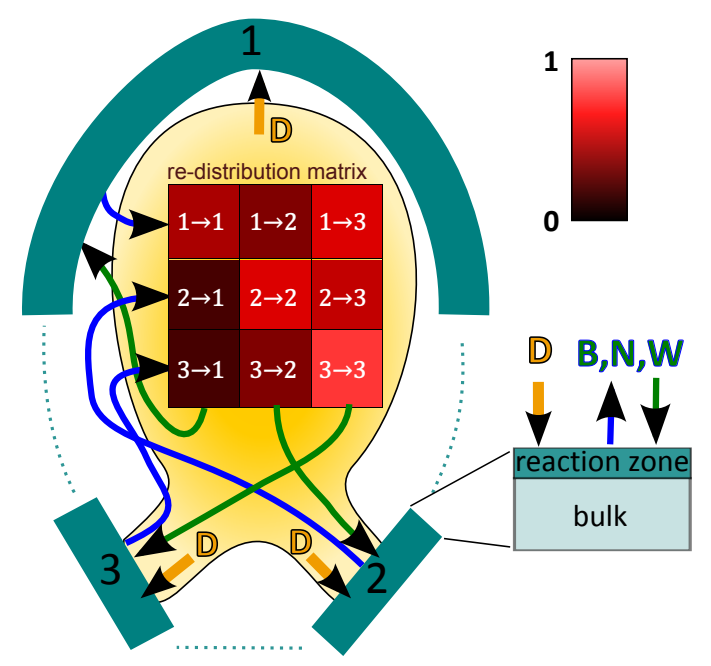

Figure 4: For the WallDYN model the wall is discretized into wall tiles. Each wall tile consists of a bulk and a reaction zone. The composition of the bulk is fixed, the composition of the reaction zone evolves according to the incoming particle fluxes. The transport of the impurities through the plasma is parameterized by the re-distribution matrix calculated with DIVIMP. The re-distribution matrix states which percentage of the material eroded from a given tile impinges on another tile. Typically the matrix has strong diagonal terms.

\subsubsection{Model for the interaction of $\mathrm{N}$ with tungsten surfaces}

As shown in Ref. [5], the BCA code SDTrimSP correctly describes the implantation of $\mathrm{N}$ in W. However, this model is computationally too expensive to be directly used in large scale migration simulations like WallDYN. Because WallDYN does not include the actual depth profile, only a simplified model for the saturation can be used. Based on the discussion given in Ref. [5], the model should limit the depth-integrated nitrogen areal density to $\sigma_{N} \leq 1 \cdot 10^{20} \mathrm{~N} / \mathrm{m}^{2}$. In this model the reflection yield is modified to reproduce the saturation of the nitrogen content:

$$
R Y^{\text {effective }}=I(C)+(1-I(C)) \cdot R Y^{\text {kinetic }}\left(\sigma_{w k}, e l, q l, w k\right)
$$

In this expression $C$ is the concentration of the saturating species and $R Y^{\text {kinetic }}$ the common, kinetic reflection yield. $I(C)$ is a function with $I(C)=0$ at small concentrations of the saturating species $\left(C<c_{0}\right)$. Between $C=c_{0}$ and $C=c_{\max }$ the value of $I(C)$ increases from zero to one to meet the conditions $I\left(C=c_{0}\right)=0$ and $I\left(C=c_{\max }\right)=1$. To improve the numerical properties a second order polynomial is employed for $I(C)$ with the additional condition of a 
continuous first derivative at $C=c_{0}$.

According to the laboratory experiments presented in Ref. [5], the maximum local concentration of $\mathrm{N}$ in tungsten is around $50 \%$. However, this value cannot be directly used as $c_{\max }$ in the WallDYN model because it is only reached in a certain depth interval, while the average $\mathrm{N}$ concentration in the uppermost nanometers is smaller. With the default value for the reaction zone thickness of $4 \mathrm{~nm}$ and a maximum concentration of $30 \%$ the nitrogen saturation sets in somewhat below $1 \cdot 10^{20} \mathrm{~N} / \mathrm{m}^{2}$. This is the value suggested for the saturation areal density by laboratory experiments and SDTrimSP simulations in Ref. [5].

A direct comparison of this WallDYN saturation model to the SDTrimSP simulations from Ref. [5] is shown in Fig. 5 for various fractions of $\mathrm{N}$ in the incoming flux. The $\mathrm{N}$ areal densities calculated with the new WallDYN model (solid lines) saturate and reasonably reproduce the SDTrimSP simulations (dashed lines) for pure N implantation or small fluences. For comparison, the dotted curve gives the result of a WallDYN simulation where the saturation model is not applied. Without the limitation the $\mathrm{N}$ areal density rises steadily, in contradiction to the experimental observations presented for example in Refs. [4, 5, 11, 19]. At high fluences and for low $\mathrm{N}$ fractions in the incoming flux WallDYN underestimates the $\mathrm{N}$ areal density. This is explained as follows: For small fluences the $\mathrm{N}$ inventory is determined by the reflection yield ${ }^{C}$ and therefore very similar in both models. At larger fluences $\mathrm{N}$ re-erosion and effusion limit the $\mathrm{N}$ accumulation. According to SDTrimSP, the recoil implantation of $\mathrm{N}$ shifts the $\mathrm{N}$ content into larger depth, from where it cannot be eroded. However, in WallDYN the depth distribution of $\mathrm{N}$ is not taken into account. Consequently the re-eroded fraction increases with decreasing $\mathrm{N}$ fraction in the incoming flux and the predicted $\mathrm{N}$ areal density consequently decreases. A possible way to correct the reaction zone model (without calculating the actual depth distribution) would be the utilization of effective, composition dependent sputter yields. Though the simple model does not yet completely agree with the SDTrimSP results, it already reproduces most of the curves shown in Fig. 13 of Ref. [5] within a factor of two. Considering that other uncertainties often limit the accuracy of material migration predictions to similar

\footnotetext{
${ }^{\mathrm{c}}$ The reflection and sputter yields are calculated in WallDYN from fits to static SDTrimSP simulations.
} 
values, the model is reasonably accurate for the simulation of $\mathrm{N}$ migration in fusion experiments.

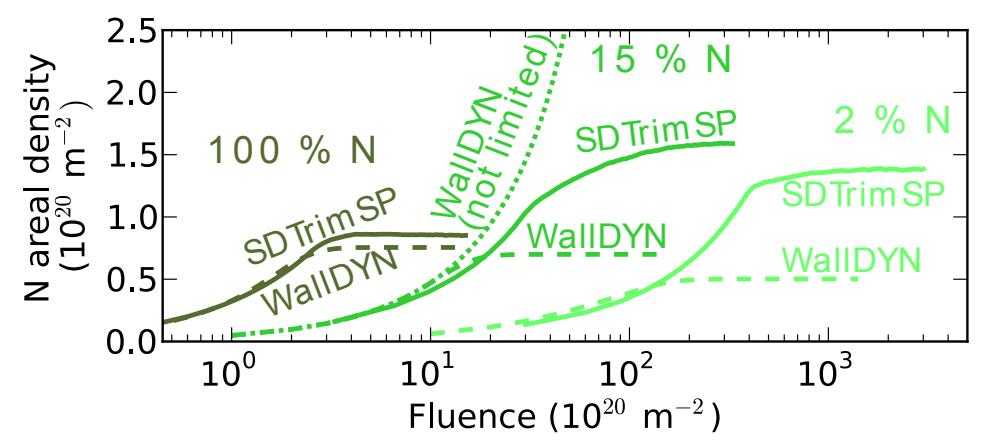

Figure 5: Comparison of the WallDYN surface model (dashed lines) to the SDTrimSP simulations (solid lines) for $E_{D}=80 \mathrm{eV} E_{N}=160 \mathrm{eV}$ presented in Ref. [5]. Without limitation (dotted curve), the $N$ content rises continuously. The numbers next to the curves indicate the $N$ percentage in the incoming flux. According to the WallDYN result presented on page 20, a few percent of the flux onto the divertor target consists of $N$ ions.

One should note that the $\mathrm{N}$ areal density in WallDYN may be increased beyond the reaction zone inventory by the transport of material from the reaction zone to the bulk, $\Gamma^{b u l k}[9] . \Gamma^{b u l k}$ also accounts for the physical process of co-deposition, where implantation depth and concentration of $\mathrm{N}$ still are limited, but as the surface continuously is covered with 'fresh' material, the area can collect more and more $\mathrm{N}$.

Due to regular boronizations which are applied to improve the plasma performance [26], parts of the AUG first wall are covered with boron. The initial wall composition in the WallDYN simulations was pure tungsten around the DIM and a mix of $80 \%$ tungsten and $20 \%$ boron for the rest of the wall. Boron, similar to tungsten, forms the stable compound BN with nitrogen. As Ref. [27] indicates that the guiding processes for the BN formation are the same as for the WN formation, the $\mathrm{N}$ concentration in the reaction zone is limited in boron containing surfaces to the same value of $30 \%$ as used for $\mathrm{W}$.

An essential loss mechanism for gaseous species like $\mathrm{N}_{2}$ is the pumping by the vacuum system. In WallDYN this has been included by setting the the sputter- and reflection yields of the wall tiles that correspond to the divertor slits to zero. In reality a part of the particles does not reach the pump but returns to the plasma, so this model should give an upper limit for the 
loss to the vacuum pumping system.

\subsubsection{Plasma backgrounds and DIVIMP simulations}

An essential input into WallDYN and DIVIMP is the plasma background, i.e. spatially resolved information about plasma parameters like electron and ion densities, temperatures and the mean ion velocity. Plasma backgrounds can be generated with sophisticated models like SOLPS [28] or with simpler models like the onion-skin model (OSM) [25].

SOLPS plasma backgrounds The simulations presented in this work are largely based on plasma backgrounds generated with the SOLPS5.0 code by Aho-Mantila et al.. A detailed description of the SOLPS simulations with a comparison to experimental data will be published elsewhere. Published comparisons of SOLPS5.0 simulations and measurements from non-seeded L-mode discharges at similar density can be found in Refs. [29, 30]. Two SOLPS plasma backgrounds are employed to reproduce the observed plasma states (see section 2.1). The first one corresponds to the plasma state without $\mathrm{N}$-seeding and higher $T_{e}$ at the outer strike line. The second solution includes the effect of $\mathrm{N}$-seeding on the plasma, reproducing the low $T_{e}$ divertor conditions.

Generally the plasma parameters in the outer divertor are reasonably matched by SOLPS plasmas. Deviations exist mostly in the inner divertor region and in the simulated ion flows [30]. Another shortcoming of SOLPS is the computational grid, which covers only the part of the SOL directly connected to both divertors via magnetic field lines. For the simulations employed in this work the gap between the SOLPS plasma and the wall was bridged with an OSM solution. Here we want to note that for the present work, which is mainly concerned with the divertor region, the inclusion of the far SOL only introduced little changes in the simulation.

To reproduce the experimental conditions the background corresponding to the non-seeded high $T_{e}$ plasma is applied from the beginning of the simulated phase at $1.3 \mathrm{~s}$ (discharge time) to $1.7 \mathrm{~s}$ and from 2.5 to $3.2 \mathrm{~s}$. The background corresponding to the N-seeded low $T_{e}$ plasma is employed from 1.7 to $2.5 \mathrm{~s}$ and from 3.2 to $4.55 \mathrm{~s}$ (see Fig. 2). This is about $0.2 \mathrm{~s}$ longer than 
the experimental flattop phase.

Plasma backgrounds based on the onion-skin model On top of this, also pure OSM plasmas were created and employed in WallDYN simulations. Firstly, this allows to create customized plasma backgrounds which help to better understand the transport of nitrogen through the plasma. Secondly, OSM plasma solutions are routinely used in the interpretation of material migration experiments, for example in Refs. [10, 32]. The comparison of simulations based on SOLPS and OSM solutions and experimental measurements allows to test the applicability of OSM results.

To allow a direct comparison between an OSM based plasma and the SOLPS plasma, the boundary conditions for the OSM plasma generation were taken from the SOLPS solution, similar to the procedure described in Ref. [31]. Because the low $T_{e}$ SOLPS solution has been found to be more appropriate for the simulation of nitrogen deposition, these boundary conditions were taken from this simulation. On the basis of these boundary conditions on the divertor targets and low field side midplane, two further OSM solutions with customized parameters have been employed for this work:

- A 'simple' OSM background, where radial profiles from SOLPS are specified as boundary conditions at the divertor target plates and the low field side midplane. With these boundary conditions, the OSM plasma exhibits a flow reversal around the X-point, which is not present in the SOLPS backgrounds.

- A background where the flows in the X-point region were modified with respect to the 'simple' background by manually prescribing the plasma flow in the X-point region. This is possible because the OSM plasmas are not fully constrained by self-consistency.

A comparison of the flow pattern of the 'simple' and the modified OSM background is shown in Fig. 6. Plots of the electron temperature, electron density and flow velocity of these plasma backgrounds can be found in Ref. [14, App. D]. 


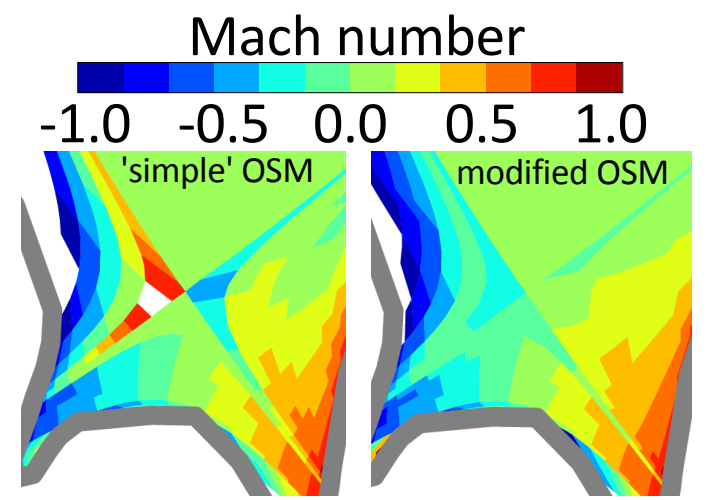

Figure 6: $D^{+}$flow patterns of the OSM plasma background in the X-point region. Positive flows are directed towards the outer divertor.

DIVIMP simulations of the impurity transport through the plasma The main result from the DIVIMP simulations, the re-distribution matrix, is shown in Fig. 16 and gives a detailed picture of the $\mathrm{N}$ transport through the plasma. The number of Monte Carlo particles launched (50000 per calculation) was chosen sufficiently large to make the resulting error in the WallDYN simulations negligible. A diffusion coefficient of $D_{\perp}=0.5 \mathrm{~m}^{2} \mathrm{~s}^{-1}$ was applied for the calculations presented in this work. This value was adopted from the SOLPS plasma background simulation and is in the typical range [32, 33]. Increasing the diffusion coefficient to $D_{\perp}=1 \mathrm{~m}^{2} \mathrm{~s}^{-1}$ leaves the outer divertor deposition unaffected and decreases the nitrogen concentration in the core plasma. The motion of ions due to classical cross field drifts is not included in DIVIMP. The impurities are launched as atoms with a cosine angular distribution and an energy of around $3 \mathrm{eV}$. This energy is in the range of half the surface binding energy, where the energy distribution of sputtered particles has its maximum [34]. However, nitrogen may enter the plasma in the form of thermal $\mathrm{N}_{2}$ or even $\mathrm{NH}_{3}$ molecules and the dissociation chains of these molecules cannot be calculated with DIVIMP. The most likely effect of molecules would be to change the spatial ionization pattern. To test the sensitivity of the ionization pattern to the initial conditions of the nitrogen atoms, a WallDYN-DIVIMP simulation with thermal initial energies of around $0.03 \mathrm{eV}$ was performed. The resulting deposition in the outer divertor was the same as for $3 \mathrm{eV}$. The impact on the core nitrogen concentration is discussed in section 4 . The results indicate that there are differences between launching $\mathrm{N}$ atoms and 
nitrogen containing molecules, but that launching $\mathrm{N}$ atoms is an acceptable approximation for the present study. Also in SOLPS simulations of AUG H-mode plasmas only a small difference was found between starting $\mathrm{N}_{2}$ molecules and $\mathrm{N}$ atoms [2].

\section{$3 \quad$ Nitrogen and boron implantation in tungsten exposed to the AUG divertor plasma}

This section first summarizes the experimental results on the deposition of nitrogen and boron on samples exposed on the divertor manipulator (DIM) of AUG to non-seeded and N-seeded plasmas and compares them to WallDYN simulations. The discrepancies which are observed between the measurements and the simulations for the $\mathrm{N}$ deposition in the non-seeded discharge and for the boron deposition are then discussed in the second part of this section. An overview of the sample exposures can be found in table 1 and Fig. 3. The result on the $\mathrm{N}$ re-erosion, studied in discharges \#29697 and \#29698, will be discussed in section 3 .

\begin{tabular}{|c|c|c|c|}
\hline & Discharge \# & $\mathrm{N}$ puff & Sample Exposure: rationale and result \\
\hline \multirow{4}{*}{$\partial_{z_{\gamma}}$} & 29695 & $\mathrm{x}$ & $\begin{array}{c}\text { Reference sample (Notable } \mathrm{N} \text { deposition } \\
\text { even without seeding) }\end{array}$ \\
\hline & 29696 & $\checkmark$ & $\mathrm{N}$ accumulation with $\mathrm{N}$ seeding \\
\hline & 29697 & $\sqrt{ }$ & \multirow{2}{*}{$\begin{array}{c}\mathrm{N} \text { Re-erosion (see section 3.1: } \mathrm{N} \text { content } \\
\text { somewhat above reference sample) }\end{array}$} \\
\hline & 29698 & $\mathbf{x}$ & \\
\hline \multirow{3}{*}{${ }_{\partial_{1}}$} & 29730 & $\checkmark$ & $\begin{array}{c}\mathrm{N} \text { accumulation (repetition of \#29696 but } \\
\text { significantly less } \mathrm{N} \text { deposition) }\end{array}$ \\
\hline & 29731 & $\checkmark$ & \multirow{2}{*}{$\begin{array}{c}\text { Fluence dependence (N content higher than } \\
\text { in \#29730, but lower than in sample } \\
\text { exposed to \#29696) }\end{array}$} \\
\hline & 29732 & $\checkmark$ & \\
\hline
\end{tabular}

Table 1: For this work 5 samples were exposed in 7 AUG discharges and afterwards analyzed by NRA for their nitrogen and boron content.

The $\mathrm{N}$ areal densities measured on the samples exposed to AUG divertor plasmas in the discharges \#29695 to \#29698 and \#29730 to \#29732 and the WallDYN prediction for the N areal density in this region are shown in Fig. $7 \mathrm{a}$. The results concerning the deposition of $\mathrm{N}$ on samples exposed to N-seeded discharges have already been discussed in Ref. [11]:

- The sample exposed only to the non-seeded discharge \#29695 already has a notable N content. 
- The $\mathrm{N}$ content of the samples exposed to the N-seeded discharges is \#29696 is up to a factor of two higher than the sample exposed to the nominally identical discharge \#29730.

- The $\mathrm{N}$ content of the sample exposed to two N-seeded discharges is comparable to the inventory of the samples exposed to one $\mathrm{N}$-seeded discharge. That means that the $\mathrm{N}$ content reaches its steady-state value within one discharge.
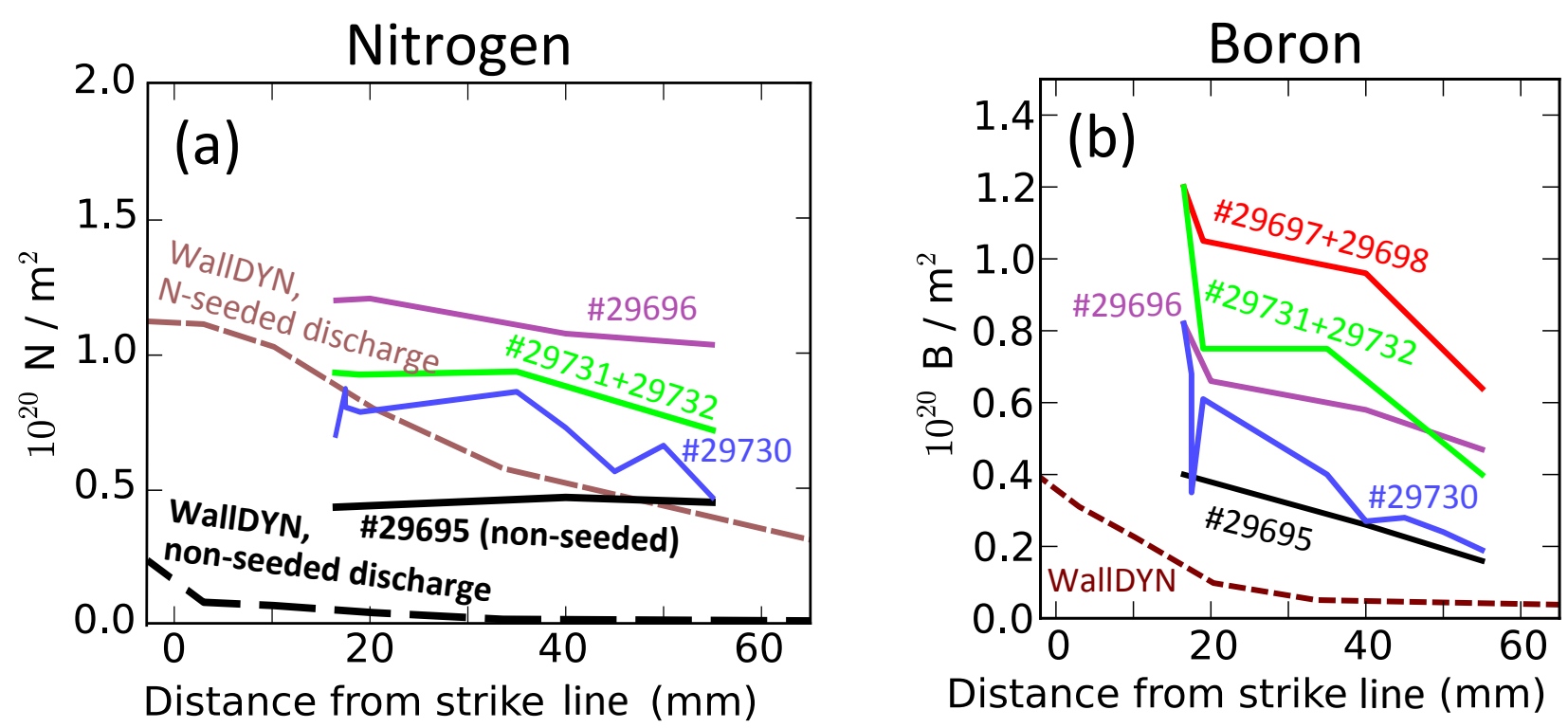

Figure 7: $N$ areal density measured on the samples exposed in the Divertor Manipulator to AUG plasmas. There is a small variation of the $N$ content as function of the poloidal position. The discharges are described in section 2.1. The outer divertor deposition of $N$ in the non-seeded discharge \#29695 (black line in (a) ) and the boron deposition of all samples (b) are underestimated by WallDYN (dashed lines). The boron deposition pattern indicates a fluence dependence.

In contrast to the deposition of $\mathrm{N}$ during $\mathrm{N}$-seeded discharges, which is reproduced quite well by the WallDYN simulations as shown in Ref. [11, the WallDYN prediction on the $\mathrm{N}$ deposition in the non-seeded discharge (dashed black curve) is much lower than the experimental result (solid black curve).

The boron deposition profiles, measured together with the $\mathrm{N}$ deposition, are shown in Fig. 7b. The boron deposition rate is similar to the $\mathrm{N}$ deposition rate, reflecting their similar abundances in the plasma, with a typical boron content of $1 \%$ [35]. The average boron content of 
the samples exposed on the second day is somewhat lower than on the samples exposed on the first day. In particular, more boron was deposited on the sample exposed to \#29696 than on the sample exposed to \#29730, so that the co-deposition of $\mathrm{N}$ with boron could have increased the $\mathrm{N}$ retention in \#29696.

Figure $7 \mathrm{~b}$ also shows the boron areal densities predicted by a WallDYN simulation of a Nseeded discharge. Boron was included in the WallDYN simulations by estimating its contribution to the initial wall configuration (see section 2.4.1). The boron deposition predicted by WallDYN is below $0.1 \cdot 10^{20} \mathrm{~B} / \mathrm{m}^{2}$ and therefore too low. Another discrepancy between the experimentally observed boron deposition and the WallDYN simulations is visible in the fluence dependence: The boron content in the simulation already has reached a dynamic equilibrium within one discharge and does not increase further with increasing fluence. This is in contrast to the experimental results for boron: The boron content increases towards the strike line and the boron content from the samples exposed to two subsequent discharges is about a factor of two larger than in the samples exposed to one discharge. This strongly indicates that the boron content in the experiment is approximately proportional to the fluence.

Summarizing, the WallDYN simulations underestimate the boron deposition in all discharges and the $\mathrm{N}$ deposition in the non-seeded discharge \#29695. In the following possible explanations for the discrepancies will be discussed:

- The discrepancy in the $\mathrm{N}$ areal density could be caused by $\mathrm{N}$ which has adsorbed on the sample surface during its transport through air. However, such a contamination cannot explain the discrepancy in the B areal density, as B is not present in the environment.

- The N source in the simulation was reduced by a factor of 10 in comparison to the N-seeded discharges for the simulation of the non-seeded discharge. This factor was estimated from residual gas analysis (suggesting a factor of 10-20 difference in the $\mathrm{N}$ partial pressure between non-seeded and N-seeded discharges, Ref. [14]) and spectroscopic measurements (indicating a factor 3-10, cf. Fig. 3). As the $\mathrm{N}$ content is given by the balance of implantation and re-erosion, it should initially be proportional to the incoming $\mathrm{N}$ flux. That 
means if the $\mathrm{N}$ source was only reduced by a factor of 3 , the simulated $\mathrm{N}$ areal density would still be too small by about a factor of 2 .

- Also the boron sources might be underestimated in the simulation. Boron enters the simulations via physical sputtering from the boron contained in the initial wall configuration. The boron influx on the DIM could be increased especially by increasing the initial boron content in the outer divertor. This, however, is in contrast to the findings that the outer divertor usually is a zone of net erosion [36], where one would not expect large amounts of boron several weeks after a boronization.

- The surface roughness of the employed samples could lead to an overestimation of the reflection coefficient or of the re-erosion in the WallDYN simulations, and thereby to an underestimation of $\mathrm{N}$ and $\mathrm{B}$ deposition. Though such an effect is not unlikely, it is difficult to estimate the effect of surface roughness from the present experiments, so that this question must be deferred to the futured

- Also the negligence of depth profile effects in the reaction zone surface model of WallDYN could lead to an overestimation of the re-erosion. This will be discussed in the following on the basis of SDTrimSP simulations.

Reaction zone models are preferred in migration simulations because of their low computational effort. However, it is known that depth profile effects can play an important role in determining the balance between erosion and deposition [38]. Because the erosion of $\mathrm{N}$ deposited in a depth of more than $1 \mathrm{~nm}$ requires the simultaneous erosion of the tungsten matrix [5], depth profile effects could reduce the re-erosion of $\mathrm{N}$ implanted into $\mathrm{W}$. The hypothesis of depth profile effects has been tested by performing SDTrimSP simulations [39, 40]. The impact angle for all species was $60^{\circ}$ as suggested by Ref. [41] and the ion fluxes are based on the WallDYN/SOLPS simulations:

- $0.1 \cdot 10^{20} \mathrm{~W} / \mathrm{m}^{2} / \mathrm{s}(100 \mathrm{eV})$

\footnotetext{
${ }^{\mathrm{d}}$ First results on this work can be found in Ref. 37.
} 

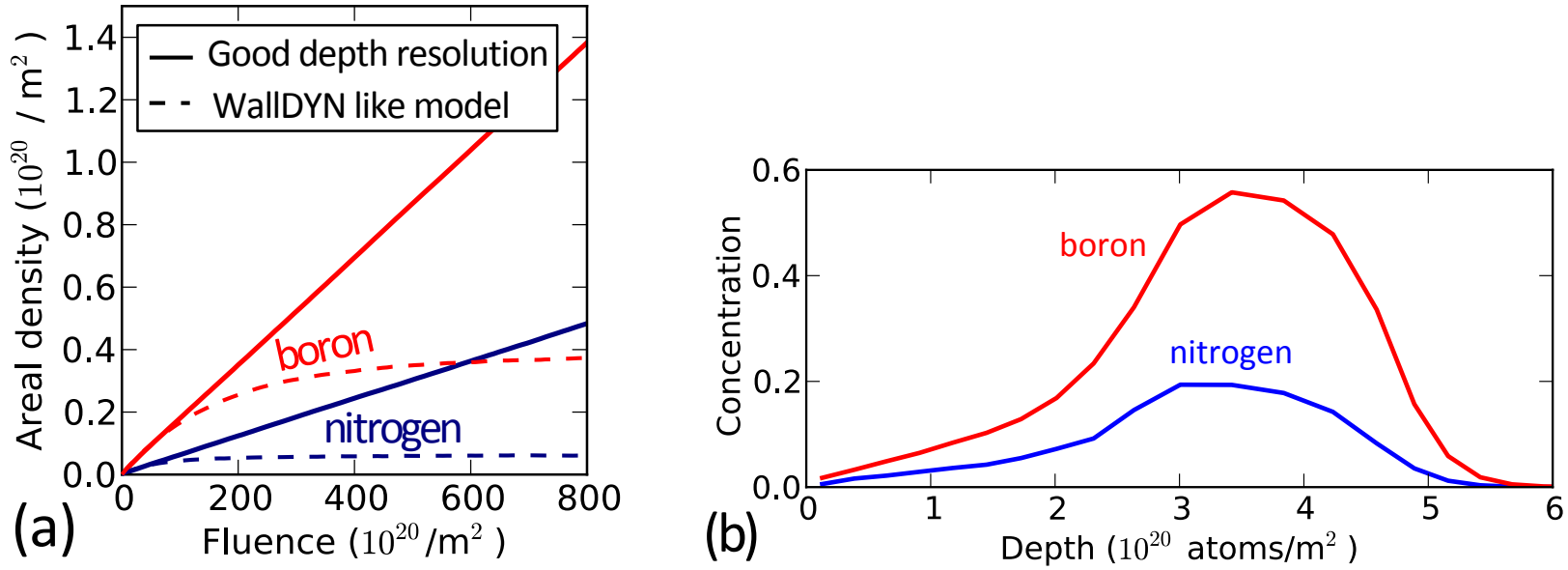

Figure 8: (a) shows the $N$ and $B$ accumulation in tungsten under $D-B-N-W$ bombardment from $S D T$ TrimSP simulations. The particle fluxes are based on a non-seeded WallDYN simulation. For the simulation with $10 \mathrm{~nm}$ tick layers (dashed lines) re-erosion leads to low steady state areal densities. In the simulation with a good depth resolution (solid lines), $N$ and $B$ areal densities rise to higher values. (b) shows the depth profiles from the simulation with a good depth resolution at a total (mainly D) fluence of $800 \cdot 10^{20} \mathrm{~m}^{-2}$. The concentrations of $B$ and $N$ peak in a depth of $3-4 \cdot 10^{20} \mathrm{~m}^{-2}(4-5 \mathrm{~nm})$. As the $N$ concentration for the present simulation remains below $50 \%$, the $N$ areal density is not yet saturated.

- $0.5 \cdot 10^{20} \mathrm{~N} / \mathrm{m}^{2} / \mathrm{s}(100 \mathrm{eV}$, flux corresponding to a non-seeded discharge)

- $1 \cdot 10^{20} \mathrm{~B} / \mathrm{m}^{2} / \mathrm{s}(100 \mathrm{eV})$

- $100 \cdot 10^{20} \mathrm{D} / \mathrm{m}^{2} / \mathrm{s}(50 \mathrm{eV})$

The dashed lines in Fig. 8a show the result from a SDTrimSP simulation with a very coarse depth resolution of $10 \mathrm{~nm}$. This simulation behaves similar to the WallDYN result, with the areal densities saturating on a rather low level. The solid lines in Fig. 8a shows a SDTrimSP simulation with a good depth resolution of $0.4 \mathrm{~nm}$. With the good depth resolution the areal densities rise linearly with the fluence and reach much higher levels, comparable to the ones found in the measurements.

As can be seen in Fig. 8b, in the simulation with a good depth resolution the $\mathrm{N}$ and $\mathrm{B}$ profiles peak in a depth of $4-5 \mathrm{~nm}$. In models with a coarse depth resolution the material is more homogeneously distributed, the concentration in the uppermost nanometer is higher and 
the resulting erosion is overestimated. Therefore, although the underestimation of $\mathrm{N}$ and $\mathrm{B}$ sources or the surface roughness might contribute to the observed discrepancy, the inclusion of depth profile effects results in a significantly better agreement between measurements and modelling.

\section{Re-erosion of retained nitrogen}

Figure 9 shows the $\mathrm{N}$ areal density profile of a sample exposed to the N-seeded discharge \#29697 and the non-seeded discharge \#29698, and the corresponding WallDYN simulation. The aim of these discharges was to study the re-erosion of previously implanted $\mathrm{N}$ in a nonseeded discharge. The $\mathrm{N}$ content in this sample is similar to the $\mathrm{N}$ content in the sample exposed to the non-seeded discharge \#29695 and significantly lower than the $\mathrm{N}$ content in the previous sample, exposed only to N-seeded discharge \#29696. This shows that the previously implanted $\mathrm{N}$ is partly re-eroded and the steady-state $\mathrm{N}$ content for a non-seeded discharge is reached within one non-seeded discharge. This measurement also proves that the $\mathrm{N}$ content in the sample exposed to \#29695 already has reached a steady state.

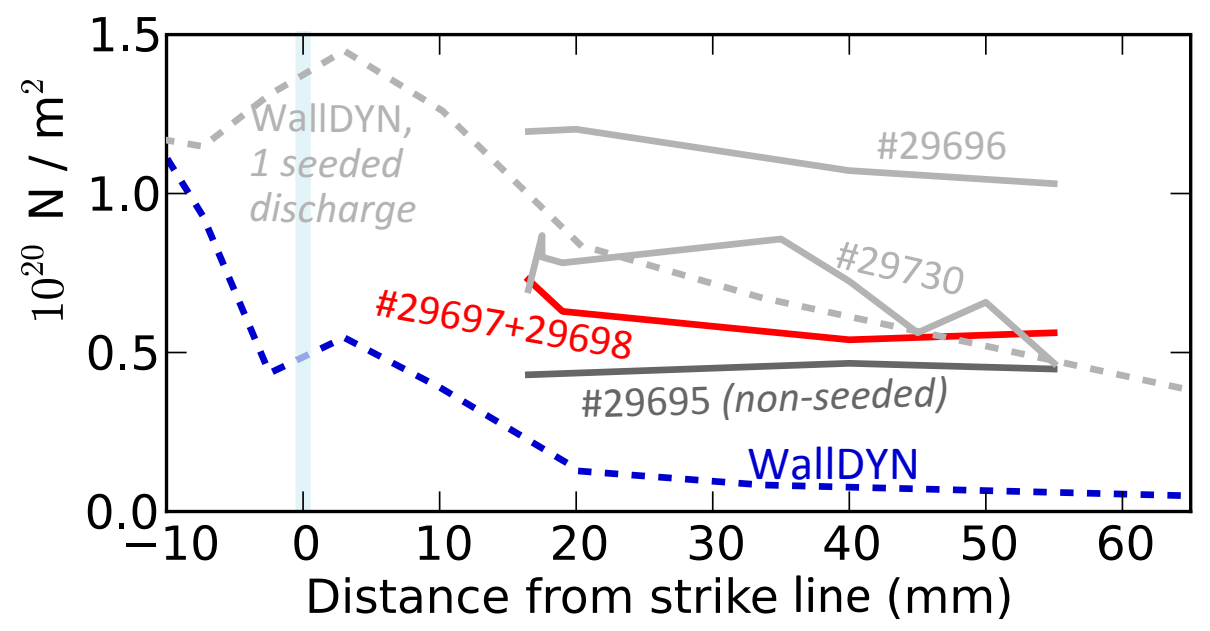

Figure 9: The red line is the $N$ content of the sample exposed to the $N$-seeded discharge \#29697 and the non-seeded discharge \#29698. The blue dashed curve is the corresponding WallDYN prediction. The $N$ inventory of some further samples is shown (gray lines) for reference.

Also the re-erosion of the previously implanted $\mathrm{N}$ was simulated with WallDYN. The initial wall composition state for this simulation was generated by simulating two subsequent N- 
seeded discharges (\#29696 and \#29697) and setting the N content of the divertor manipulator region to zero in between. Then this initial wall condition (the gray dashed curve in Fig. 9) was used for a WallDYN simulation without $\mathrm{N}$ puff and based on the high $T_{e}$ (non-seeded) plasma background. In comparison to the measurements, the simulated $\mathrm{N}$ areal density is again too low. This becomes even clearer from the "depth distribution" of the remaining N. It is almost completely removed from the reaction zone and only $\mathrm{N}$ transported to the bulk, which cannot be re-eroded in the current WallDYN model, remains [14, Fig. 5.4]. As discussed in the previous section possible reasons for the underestimation of the $\mathrm{N}$ content in WallDYN are the negligence of depth profile effects in WallDYN or a $\mathrm{N}$ source which is not included in the simulation. Spectroscopic measurements performed during \#29698 are given in Fig. 10b and hint to an overestimation of the $\mathrm{N}$ re-erosion in WallDYN.

\section{Nitrogen fluxes and distribution in the plasma from spectroscopic measurements}

This section discusses the spectroscopic measurements of $\mathrm{N}$ fluxes and distribution in the plasma and gives a comparison to a synthetic spectroscopy diagnostic, which recently has been added to WallDYN [10, 14. An overview of some spectroscopic measurements in all discharges has already been given in Fig. 3. The positions of the spectroscopic lines of sight used for this work are shown in Fig. 1 .

\subsection{Passive spectroscopy measurements}

Figure 10 shows the time evolution of two spectroscopic lines of sight viewing the region around the outer strike line. The line of sight used for Fig. 10a views the lower end of the divertor manipulator. In this region the variation between high and low $T_{e}$ state is comparably small and the $\mathrm{N}$ puff leads to an increase in the emitted number of photons. The simulation nicely reproduces the observed behavior. Figure $10 \mathrm{~b}$ shows a line of sight, where the $\mathrm{N}$ line intensity 
only increases in the beginning of the N seeded phases of \#29696 (gray curve) and \#29697 (light green curve) and may even drop with an increasing $\mathrm{N}$ content. In the WallDYN simulation (dashed dark green curve) the intensity rises more quickly than in the experiment, probably due to the delay caused in the experimental $\mathrm{N}_{2}$ puff by the transport through the $3 \mathrm{~m}$ long tube [14, Ch. 5.2.1]. As discussed in section 2.4.2, the simulation switches between the high $T_{e}$ and the low $T_{e}$ plasma background at $1.7 \mathrm{~s}, 2.5 \mathrm{~s}$ and $3.2 \mathrm{~s}$. With this setup, WallDYN gives a lower spectroscopic $\mathrm{N}$ line intensity during the high $T_{e}$ phases than during the $\mathrm{N}$-seeded low $T_{e}$ phase, similar to the experimental observation. This indicates that for the observed region the number of emitted photons decreases with increasing $\mathrm{N}$ content, because the number of photons emitted per ion decreases with decreasing plasma temperature.
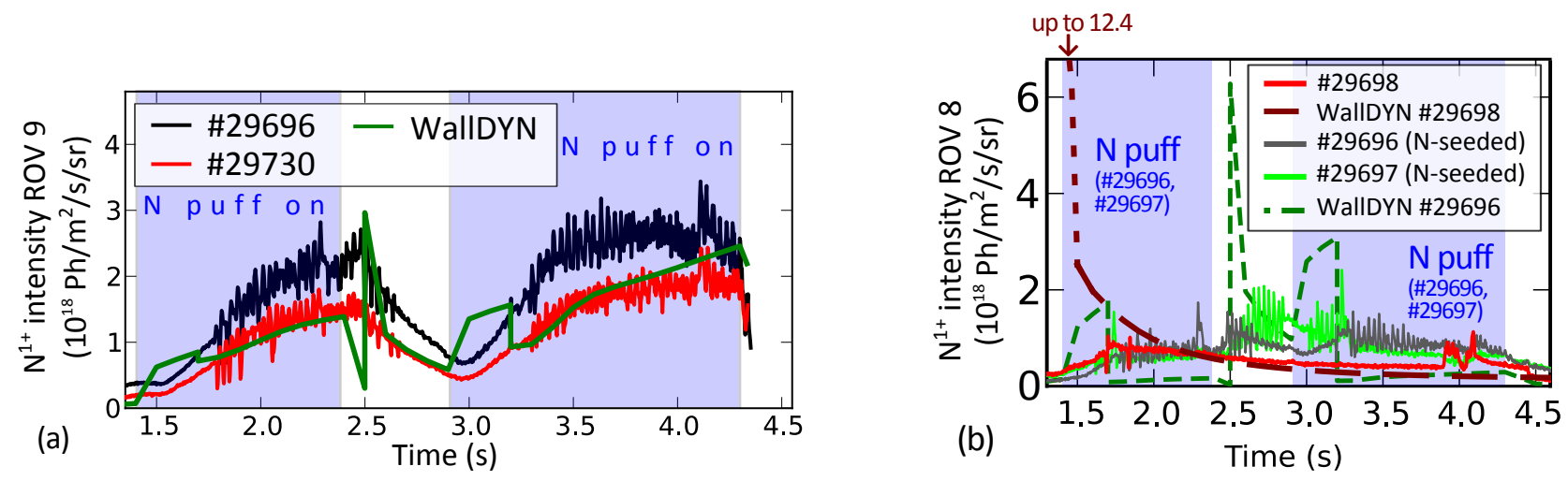

Figure 10: $N^{1+}$ emission close to the outer strike line. The blue shaded areas indicate the $N_{2}$ puff during the discharges \#29696, \#29697 and \#29730. (a) shows a line of sight viewing the lower part of the divertor manipulator, where the $N$ intensity rises during the $N$-seeded phases and the time evolution is nicely reproduces by the simulations. (b) shows a line of sight between the divertor manipulator and the strike line where the emission in the $N$-seeded discharges is strongly affected by the alterations between high $T_{e}$ and low $T_{e}$ phases and the divertor plasma oscillations. In the non-seeded discharge \#29698, $N$ is re-eroded from the walls.

Discharge \#29698 (red curve) was performed to study the re-erosion of $\mathrm{N}$ retained from the previous discharges. The initial $\mathrm{N}$ content is higher than in \#29696 and the $\mathrm{N}$ line emission decreases with time. This probably reflects the re-erosion of $\mathrm{N}$ from the surfaces, though slight changes in the plasma conditions may contribute to this intensity variation. The dashed dark red curve shows a WallDYN simulation of \#29698. This simulations employs the high $T_{e}$ plasma 
background to a wall containing nitrogen from the previous (simulated) discharges. The sharp temperature increase from the low $T_{e}$ state, used to simulate the wall loading, to the high $T_{e}$ state causes very high initial $\mathrm{N}$ fluxes and an initial simulated intensity of almost $13 \cdot 10^{18} \mathrm{Ph} / \mathrm{m}^{2} / \mathrm{s} / \mathrm{sr}$. The simulated $\mathrm{N}$ intensities stay above the measured ones until $2.5 \mathrm{~s}$. Towards the end of the discharge the $\mathrm{N}$ intensities predicted by the simulation become too low. Consistent with section 3. this indicates that the $\mathrm{N}$ erosion in WallDYN is too fast compared to the experiment.

The $\mathrm{N}$ intensities measured with various lines of sight at a fixed time of $3.75 \mathrm{~s}$ in \#29696 and \#29730 are presented in Fig. 11. This plot shows measured and simulated intensities for the low ionization states of $\mathrm{N}$. The $\mathrm{x}$-axis gives the angle between the line of sight and the horizontal direction as indicated in Fig. 1. The emission from neutral $\mathrm{N}$ atoms is shown in Fig. 11a. Here the relative distribution of the emitted radiation, originating mainly from the outer strike line, is well reproduced by the simulations. The difference between the $R O N$ and $R O V$ lines of sight at $20-40^{\circ}$ may be caused by their alignment on and between the wall tiles, respectively, as discussed in section 2.2. The good agreement in the emission distribution can also be seen in Fig. 12, which shows the simulated $\mathrm{N}^{0}$ emission pattern and a camera image obtained with a filter for the corresponding spectral region of around $747 \mathrm{~nm}$. However, in the simulation the absolute values are a factor of ten higher than the measured ones. One possible reason is the uncertain calibration for the wavelength region around $747 \mathrm{~nm}$ : For the low field side lines of sight $\left(0-40^{\circ}\right)$ the calibration is based on an extrapolation from lower wavelengths. For the high field side lines of sight (around $120^{\circ}$ ), no calibration is available so only an average calibration factor was applied. Another possible reason for the discrepancy between simulated and measured intensities may be the generation of $\mathrm{N}^{1+}$ ions by dissociative ionization directly from $\mathrm{N}_{2}^{z+}$ or $\mathrm{NH}_{y}^{x+}$ molecules, without the appearance of neutral $\mathrm{N}$ atoms [43].

The emission from $\mathrm{N}^{1+}$ was measured with properly calibrated spectrometers and is shown in Fig. 11b. Regarding the variation of the measured intensities in nominally identical discharges and the variation of the emissivity with the plasma conditions (see Fig. 10 ) the simulated intensities agree with the measured ones reasonably well in the outer divertor, where SOLPS should give the best reproduction of the plasma parameters [30], and the X-point region. There 


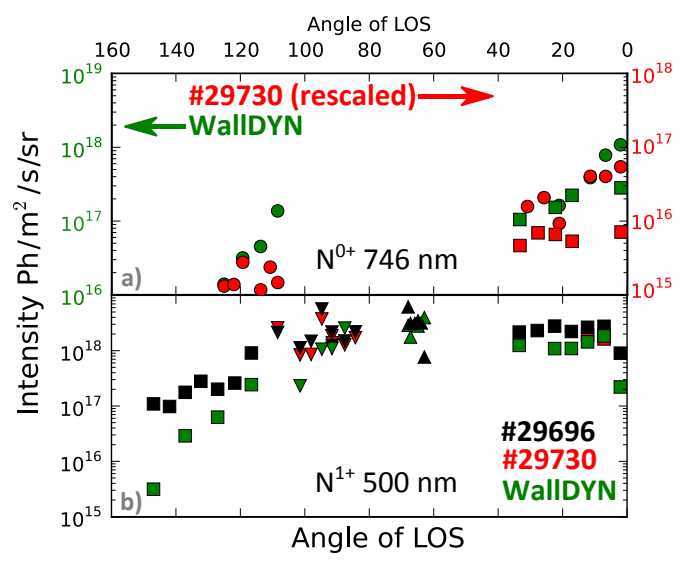

Figure 11: Comparison of measurements from passive divertor spectroscopy to synthetic data from a WallDYN simulation during the second $N$ seeded phase at $3.75 \mathrm{~s}$. The $x$-axis is the angle between the line of sight and the horizontal direction (see Fig. 1). The symbols indicate different lines of sight: $\mathbf{\square}$ are ROV and RIV lines of sight, - RON and RIN lines of sight, $\boldsymbol{\Delta}$ DOT lines of sight and $\boldsymbol{\nabla}$ ZIV and ZON lines of sight. The color distinguishes between experimental and simulated values. Figure part (a) for neutral $N$ emission employs different $y$-axes for experiment and simulation and the calibration for these lines of sight is associated with a large uncertainty (see section 2.2). Timetraces of the two righmost measurements in subfigure (b) are shown in Fig. 10. Within the uncertainties (which arise from the reproducibility of the measurements and accuracy of the plasma background and emissivity values) the $N$ distribution and fluxes are reproduced by the simulation. The $N$ fluxes from the walls for $t=2.3 \mathrm{~s}$ are given in Fig. 16. 
is a larger discrepancy in the inner divertor, however, it should be noted that the plasma conditions in this region are difficult to simulate with SOLPS while the emissivity at low temperatures is very sensitive to the plasma conditions. The relative comparison of different lines of sight shows that the simulated intensities have especially a somewhat more pronounced spatial dependence than the measured intensities.
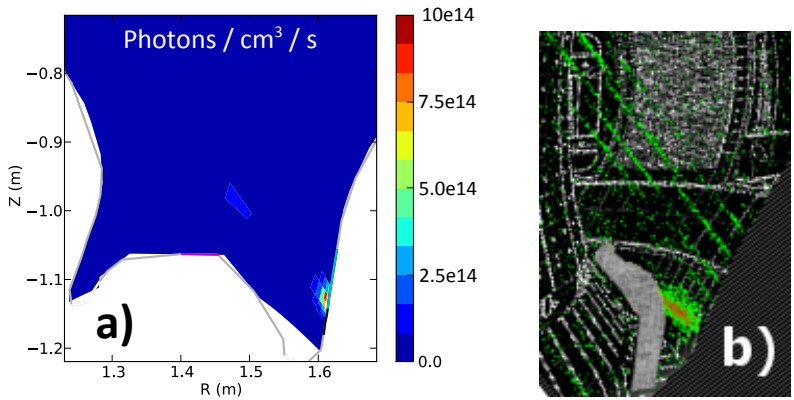

Figure 12: Emission from neutral $N$ atoms $(747 \mathrm{~nm})$ at $3.7 \mathrm{~s}$ calculated with the synthetic spectroscopy of WallDYN (a) and measured with a filtered camera (b). The inner divertor region in the camera image is corrupted by deuterium radiation.

\subsection{Core nitrogen content}

The applicability of power load control by impurity seeding depends on a low concentration of the seeded impurities in the core plasma . The concentration of $\mathrm{N}$ in the core plasma, measured by charge exchange recombination spectroscopy (CXRS), was shown for all discharges in Fig. 3. In discharge \#29695 the $\mathrm{N}$ background leads to a core concentration of about $0.2 \%$. During the N-seeded discharges the core $\mathrm{N}$ concentration rises to $0.4-0.6 \%$. The core $\mathrm{N}$ concentration at the beginning of each discharge is 0.15 to $0.2 \%$.

A comparison of the core $\mathrm{N}$ concentration to the NII emission measured with the ZIV1 line of sight shows that this emission closely follows the core $\mathrm{N}$ concentration. This line of sight views the high field side main wall from the inner divertor (magenta curve in Fig. 3, line of sight is shown in Fig. 1) and the emission follows the core $\mathrm{N}$ concentration even more closely than at lines of sights viewing the outer limiters. This indicates that the core $\mathrm{N}$ concentration is related to the $\mathrm{N}$ fluxes from this high field side region. 


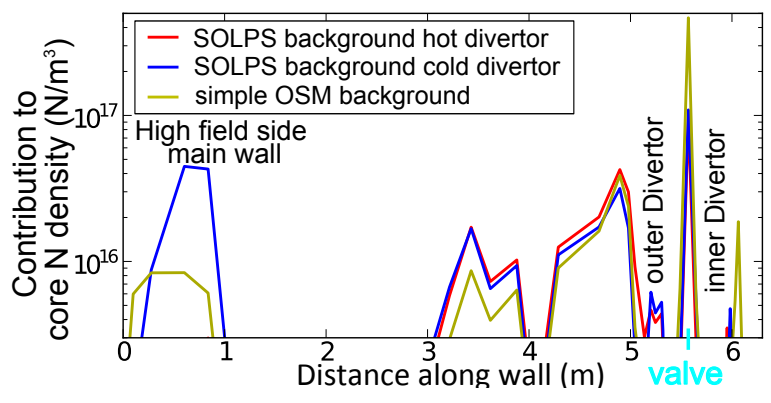

Figure 13: Sources of $N$ in the core plasma at $2.3 \mathrm{~s}$ (end of first $N$-seeding phase) from WallDYN simulations. The $x$-axis is the distance along the wall, starting above the inner divertor. The largest source is the $N$ puff. For the low $T_{e}$ background (blue curve) also the high field side main wall gives a significant contribution to the core $N$ density.

Figure 13 shows the WallDYN-DIVIMP prediction for the contribution of each wall tile to the core $\mathrm{N}$ content at $2.3 \mathrm{~s}$. The red and the blue curve were calculated with the high and the low $T_{e}$ SOLPS plasma background, respectively. The yellow curve is based on the 'simple' OSM plasma. For all simulations the N puff presents the strongest contribution to the $\mathrm{N}$ core content at this time. However, the OSM based simulation predicts a factor of four stronger contribution than the simulations based on the SOLPS plasma backgrounds. The contribution from the puff region to the core $\mathrm{N}$ concentration is stronger than the contribution from the outer divertor region, though the neutral $\mathrm{N}$ fluxes from the outer divertor target plate are larger than the flux from the puff region (see Fig. 16). The DIVIMP simulations show that this is caused by the higher probability of atoms starting from the puff region to reach the core plasma.

Besides the puff location, in all simulations $\mathrm{N}$ emitted from the baffle above the outer divertor contributes to the core $\mathrm{N}$ content. A notable difference between the SOLPS based simulations arises in the contribution from the high field side wall. Figure 13 shows that for the low $T_{e}$ SOLPS background $\mathrm{N}$ is transported to the high field side wall, so that this position becomes a comparably strong source for the core $\mathrm{N}$ content. These findings are in agreement with the previous conclusion that the high field side $\mathrm{N}$ fluxes, measured by the ZIV1 line of sight, are closely related to the core $\mathrm{N}$ concentration.

Figure 14 shows the time evolution of the core N concentrations from WallDYN simulations and the measurement from discharge \#29730 (the N-seeded discharge with the lowest N con- 


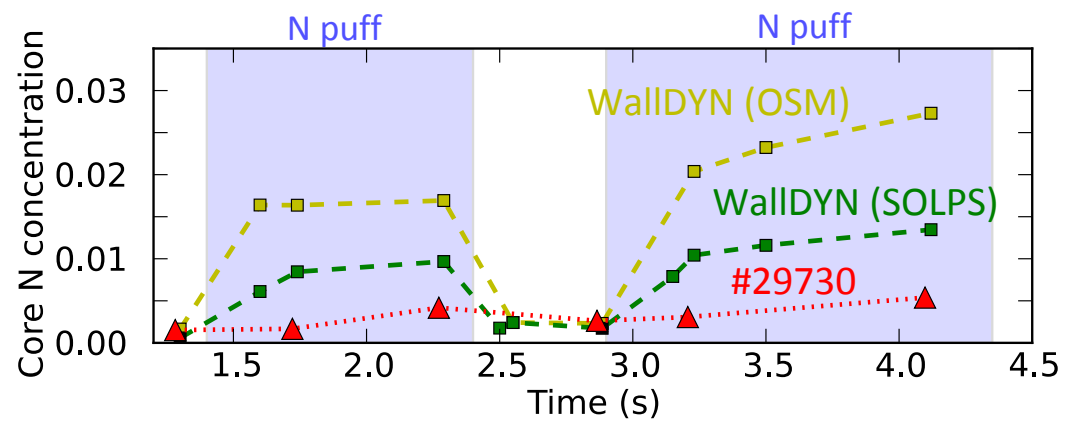

Figure 14: $N$ concentration in the core plasma measured in discharge \#29730 (М) and simulated with WallDYN-DIVIMP. Especially the WallDYN simulation based on the OSM plasma overestimates the $N$ concentration in the $N$-seeded phases.

centration). The green curve is the standard SOLPS based WallDYN simulation. It switches between both SOLPS backgrounds according to the measured time dependence in the plasma parameters (see sections 2.1 and 2.4.2). The core concentration in the N-seeded phases calculated with this simulation is about a factor of two above the measured values. Considering the simple core transport model used in DIVIMP, this is still a reasonable agreement. The WallDYN simulation based on the 'simple' OSM plasma (yellow curve) exhibits an even higher $\mathrm{N}$ concentration, which is a factor 4 above the measured values. As already observed for the divertor spectroscopy, the $\mathrm{N}$ content in the simulations rises faster than in the experimental measurement. This difference has been attributed to the delay of the experimental $\mathrm{N}_{2}$ puff by the transport through the $3 \mathrm{~m}$ long tube, therefore the time evolution is not analyzed in more detail.

\section{Impact of neutral energy, ion flows and temperature gradient force}

This section discusses the difference between the core $\mathrm{N}$ content predicted on the basis of SOLPS and the OSM backgrounds and the importance of different processes in the SOL controlling the core impurity density. A similar analysis for the processes controlling the $\mathrm{N}$ deposition can be found in Ref. [14, Ch. 5.1.3].

From Fig. 13 it is obvious that the transport of $\mathrm{N}$ from the puff region to the main plasma is very important for the core $\mathrm{N}$ concentration. The DIVIMP simulations show that only $5 \%$ 
of the $\mathrm{N}$ reaching the core from the puff location are ionized in the core plasma. That means that $\mathrm{N}$ enters the core region mainly in the form of ions. Two important contributions to the movement of the ions are the background ion flow and the temperature gradient force. Also the ionization location could still play a role in the transport of the impurities to the core plasma. To test the effect of these contributions some further WallDYN calculations have been performed.

The ionization mean free path $\lambda_{i z} \propto v_{\text {neutral }}$ increases with the initial velocity of the neutral $v_{\text {neutral }}$. The impact of the ionization pattern on the WallDYN simulations was therefore tested by varying the initial energy of the particles in DIVIMP. The cyan curve in Fig. 15 is based on DIVIMP calculations where the $\mathrm{N}$ atoms were launched with thermal velocities. This simulation reproduces the absolute core concentrations better than the standard simulation (green curve, initial energy of atoms is a few $\mathrm{eV}$ ). Because the $\mathrm{N}_{2}$ puff is the main source for the core $\mathrm{N}$ content, this result indicates that the dissociation of the puffed $\mathrm{N}_{2}$ molecules is better represented by thermal atoms than by energetic atoms (which could be generated in the dissociation process). This is in agreement with the finding of Ref. [43], that the dominant ionization path for $\mathrm{N}_{2}$ is via ionization of the thermal $\mathrm{N}_{2}$ molecules and subsequent dissociative ionization. That the initial velocity plays an important role, though the ionization in the core plasma is small, can be understood by applying the picture of the Engelhardt model [44] to the private flux region: With increasing penetration depth the ionization source is further inside the plasma. Thereby, the fraction of $\mathrm{N}$ ions which crosses the separatrix and diffuses into the main plasma increases.

The violet curve in Fig. 15 shows a WallDYN simulation based on DIVIMP calculations with the temperature gradient force switched off. One can see that this strongly reduces the predicted core $\mathrm{N}$ concentration below the measured values. This confirms the importance of this term for the impurity transport out of the divertor region, into the main chamber SOL.

Finally, the orange curve in Fig. 15 is based on the OSM solution with the adapted background flow profile (see section 2.4.2). The resulting core $\mathrm{N}$ concentration is very similar to the one obtained with the SOLPS backgrounds and gives an acceptable match to the experimental result. This indicates that the frictional coupling between the $\mathrm{N}$ ions and the reversed plasma 


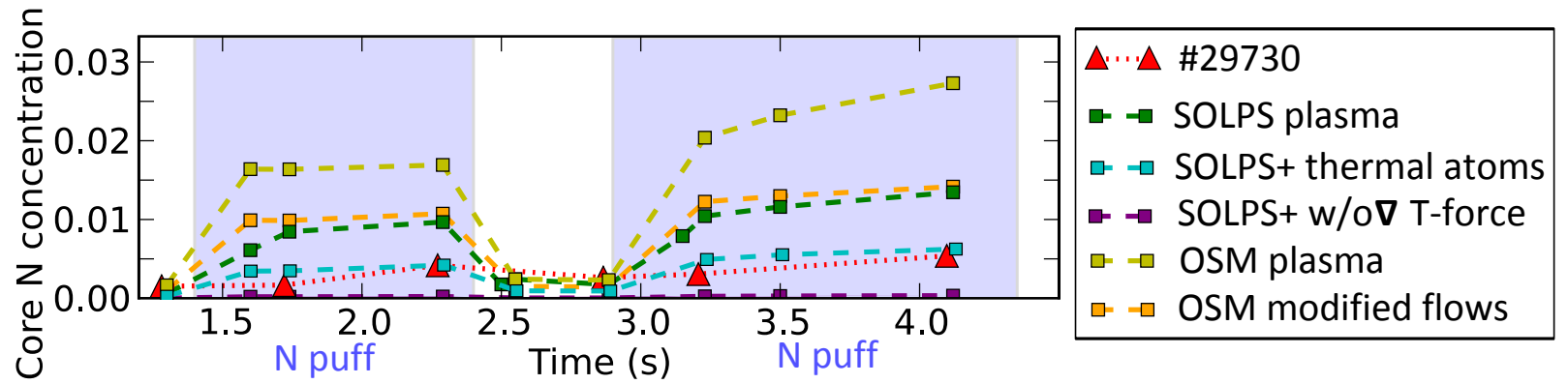

Figure 15: Core $N$ concentration calculated with different models. Starting the atoms in the DIVIMP simulation (on the SOLPS backgrounds) with thermal velocity gives the best agreement with the experimental measurement. Without temperature gradient forces the predicted core concentration drops almost by a factor of 50. An adjustment of the X-point region flows in the OSM plasma reduces the predicted $N$ concentration to the level of the SOLPS based simulation.

flow, appearing spuriously in the simple OSM background, pushed the $\mathrm{N}$ ions upwards towards the main plasma. Similar to the presented result with the SOLPS backgrounds, the core N content should drop further when the atoms in DIVIMP were launched with thermal velocity.

The reduction of the core concentration caused by the modified flow pattern around the $\mathrm{X}$-point indicates that this flow pattern was the main reason for the deviation from the SOLPS based simulations. The physical picture emerging from this analysis can be summarized as follows: Due to the local ionization source, the highest $\mathrm{N}$ concentration appears in the private flux and the divertor region (see also Ref. [14, Ch. 5.2]). With a higher initial velocity the ionization source moves radially inwards. The background ion flow and the temperature gradient force control the transport of nitrogen from the divertor region to above the X-point, where the nitrogen can diffuse into the core plasma.

\section{$5 \quad$ Summary}

This work presented measurements of the $\mathrm{N}$ and $\mathrm{B}$ accumulation on samples exposed to AUG divertor plasmas, spectroscopic measurements of the $\mathrm{N}$ fluxes and distribution in the plasma and WallDYN-DIVIMP simulations of these measurements. First, a method to include the saturation of $\mathrm{N}$ in $\mathrm{W}$ surfaces in the reaction zone model of WallDYN was presented, which for 
the first time allows quantitative predictions of the $\mathrm{N}$ migration. With this model, the WallDYNDIVIMP simulations of $\mathrm{N}$-seeded discharges reproduce the deposition of $\mathrm{N}$ in the outer divertor quite well. However, the $\mathrm{N}$ surface content in non-seeded discharges and the deposition of $\mathrm{B}$ in the net erosion region at the outer strike line were underestimated by WallDYN. This indicates that depth profile effects, which are neglected in WallDYN, may lead to an overestimation of the erosion of light species from a tungsten matrix. It should be noted, that WallDYN is mostly used to simulate the long term wall evolution, where the depth profile effects may not be as strong as for the dynamic situation at small fluences. Still, for critical regions it is recommended to check WallDYN predictions by applying the impurity fluxes calculated with WallDYN in SDTrimSP simulations.

The analysis of a sample which was first exposed to a N-seeded discharge and then to the subsequent non-seeded discharges shows that nitrogen is re-eroded from the surface. Within one discharge the $\mathrm{N}$ content in the surface drops almost to the level of a surface which was only exposed to a non-seeded discharge.

A good agreement of the WallDYN simulations with spectroscopic measurements of the ion distribution could be reached in the outer divertor and in the core plasma. So far, it was not possible to decide whether the remaining discrepancies, for example in the photon emission from neutral $\mathrm{N}$ atoms, are due to deficiencies in the simulations or due to uncertainties in the measurements. Simulations based on a simple OSM background exhibit a much larger deviation from the experimental results than simulations based on the SOLPS plasma backgrounds. However, with additional knowledge on the plasma parameters (in this case the flow pattern around the X-point from the SOLPS simulations) it is possible to generate OSM plasma backgrounds that give a good agreement to the measurements. This shows that OSM plasmas should only be used for migration simulations if the plasma can also be well characterized in the divertor volume.

Regarding the transport of nitrogen to the core plasma, the simulations show that the main sources for the present plasma conditions are the gas puff, the outer baffle and the high field side main wall. The amount of nitrogen in the core plasma depends on a a variety of processes: 
The friction with the background plasma flow in the $\mathrm{X}$-point region, the $\mathrm{N}$ ionization pattern and the temperature gradient force.

This work was part of an effort to combine laboratory experiments, computer simulations and tokamak experiments to develop a consistent picture of the $\mathrm{N}$ migration in tokamaks with a full metal wall. Based on this effort, it was possible for the first time to quantitatively simulate the $\mathrm{N}$ deposition in $\mathrm{N}$-seeded discharges. In the next step the new WallDYN model will be applied to tokamaks with Be main wall. To this end also the $\mathrm{N}$ saturation model has been improved to make it applicable to the implantation of $\mathrm{N}$ in Be [45].

\section{Acknowledgment}

We thank L. Gao for providing the calibration samples for the NRA measurements of the N content and R.M. McDermott and R. Dux for the evaluation of the CXRS measurements. This work has been carried out within the framework of the EUROfusion Consortium and has received funding from the European Unions Horizon 2020 research and innovation programme under grant agreement number 633053. The views and opinions expressed herein do not necessarily reflect those of the European Commission.

\section{References}

[1] A. Kallenbach, M. Balden, R. Dux, et al., Plasma surface interactions in impurity seeded plasmas, J. Nucl. Mater 415, S19 (2011), http://dx.doi.org/10.1016/j.jnucmat. 2010.11 .105

[2] F. Reimold, M. Wischmeier, M. Bernert, et al., Experimental Studies and Modeling of Complete H-Mode Divertor Detachment in ASDEX Upgrade, J. Nucl. Mater. 463, 128 (2015), http://dx.doi.org/10.1016/j.jnucmat.2014.12.019 
[3] M. Wischmeier, The ASDEX Upgrade team and JET EFDA contributors, High density operation for reactor-relevant power exhaust, J. Nucl. Mater. 463, 22 (2015), http://dx. doi.org/10.1016/j.jnucmat.2014.12.078

[4] K. Schmid, A. Manhard, Ch. Linsmeier, et al., Interaction of nitrogen plasmas with tungsten, Nucl. Fusion 50, 025006 (2010), http://dx.doi.org/10.1088/0029-5515/50/2/ 025006

[5] G. Meisl, K. Schmid, O. Encke, et al., Implantation and erosion of nitrogen in tungsten, New J. Phys. 16, 093018 (2014), http://dx.doi.org/10.1088/1367-2630/16/9/093018

[6] P. Petersson, A. Hakola, J. Likonen, et al., Injection of nitrogen-15 tracer into ASDEXUpgrade: New technique in material migration studies, J. Nucl. Mater. 438, S616 (2013), http://dx.doi.org/10.1016/j.jnucmat.2013.01.129

[7] L. Gao, W. Jacob, et al., Phys. Scr. T159, 014023 (2014), http://dx.doi.org/10.1088/ 0031-8949/2014/T159/014023

[8] A. Kallenbach, R. Dux, J. Fuchs, et al., Divertor power load feedback with nitrogen seeding in ASDEX Upgrade, Plasma Phys. Control. Fusion 52 055002 (2010), dx.doi.org/10. $1088 / 0741-3335 / 52 / 5 / 055002$

[9] K. Schmid, M. Reinelt, and K. Krieger, An integrated model of impurity migration and wall composition dynamics for tokamaks, J. Nucl. Mater. 415, S284 (2011), http://dx. doi.org/10.1016/j.jnucmat.2011.01.105

[10] K. Schmid, K. Krieger, et al., J. Nucl. Mater. 463, 66 (2015), http://dx.doi.org/10. $1016 / j \cdot j n u c m a t .2014 .11 .109$

[11] G. Meisl, K. Schmid, M. Oberkofler, Nitrogen retention in ASDEX Upgrade, J. Nucl. Mater. 463, 668 (2015), http://dx.doi.org/10.1016/j.jnucmat.2014.10.031 
[12] D. Neuwirth, V. Rohde, T. Schwarz-Selinger, and ASDEX Upgrade Team, Formation of ammonia during nitrogen-seeded discharges at ASDEX Upgrade, Plasma Phys. Control. Fusion 54085008 (2012), http://dx.doi.org/10.1088/0741-3335/54/8/085008

[13] M. Oberkofler, D. Douai, S. Brezinsek, et al., First nitrogen-seeding experiments in JET with the ITER-like Wall, J. Nucl. Mater 438, S258 (2013), http://dx.doi.org/10.1016/ j.jnucmat.2013.01.041

[14] G. Meisl, Nitrogen implantation in tungsten and migration in the fusion experiment ASDEX Upgrade, PhD thesis, Technische Universität München, 2015, http://hdl.handle. net/11858/00-001M-0000-0025-7492-1

[15] H.F. Winters, E. Taglauer, Sputtering of chemisorbed nitrogen from single-crystal planes of tungsten and molybdenum, Phys. Rev. B 35, 2174 (1987), http://dx.doi.org/10. 1103/PhysRevB.35.2174

[16] L. Aho-Mantila, X. Bonnin, D.P. Coster, et al., Model-Based Radiation Scalings for the ITER-like Divertors of JET and ASDEX Upgrade, J. Nucl. Mater. 463, 546 (2015), http: //dx.doi.org/10.1016/j.jnucmat.2014.11.049

[17] L. Aho-Mantila, D. Coster, M. Wischmeier, In 41st EPS Conference on Plasma Physics

[18] C. Ruset, E. Grigore, et al., Phys. Scr. T128, 171 (2007), http://dx.doi.org/10.1088/ $0031-8949 / 2007 / \mathrm{T} 128 / 033$

[19] A. Hakola, M.I. Airila, et al., Global migration of impurities in tokamaks, Plasma Phys. Control. Fusion 55, 124029 (2013), http://dx.doi.org/10.1088/0741-3335/55/12/ 124029

[20] S. Potzel, M. Wischmeier, et al., A new experimental classification of divertor detachment in ASDEX Upgrade, Nucl. Fusion 54, 013001 (2014), http://dx.doi.org/10.1088/ $0029-5515 / 54 / 1 / 013001$ 
[21] K. Behringer, H.P. Summers, B. Denne, et al., Spectroscopic determination of impurity influx from localized surfaces, Plasma Phys. Control. Fusion 31, 2059 (1989), http://dx.doi.org/10.1088/0741-3335/31/14/001

[22] H.P. Summers, ADAS User Manual 2.6, http://www.adas.ac.uk./manual.php(2004).

[23] E. Viezzer, T. Pütterich, R. Dux and R.M. McDermott, High-resolution charge exchange measurements at ASDEX Upgrade, Rev. Sci. Instrum. 83, 103501 (2012), http://dx. doi.org/10.1063/1.4755810

[24] P.C. Stangeby, C. Farrell, S. Hoskins and L. Wood, Monte Carlo modelling of impurity ion transport for a limiter source/sink, Nucl. Fusion 28, 1945 (1988), http://dx.doi.org/ $10.1088 / 0029-5515 / 28 / 11 / 003$

[25] P.C. Stangeby, J.D. Elder, Calculation of observable quantities using a divertor impurity interpretive code, DIVIMP, J. Nucl. Mater 196, 258 (1992), http://dx.doi.org/10. 1016/S0022-3115(06)80042-5

[26] V. Rohde, R. Dux, A. Kallenbach, et al., Wall conditioning in ASDEX Upgrade, J. Nucl. Mater. 363, 1369 (2007), http://dx.doi.org/10.1016/j.jnucmat.2007.01.200

[27] W. Möller, D. Bouchier, O. Burat, and V. Stambouli, Computer simulation of boron nitride deposition by ion-beam-assisted evaporation, Surf. Coat. Technol. 45, 73 (1991), http: //dx.doi.org/10.1016/0257-8972(91)90208-E

[28] R. Schneider, X. Bonnin, K. Borrass, et al., Plasma Edge Physics with B2-Eirene, Contrib. Plasma Phys. 46, 3, http://dx.doi.org/10.1002/ctpp.200610001

[29] M. Wischmeier, X. Bonnin, D. P. Coster, et al., Simulating the Role of Intrinsic Carbon Impurities in the Divertor Detachment of ASDEX Upgrade, Contrib. Plasma Phys. 48, 249 (2008), http://dx.doi.org/10.1002/ctpp. 200810043

[30] L. Aho-Mantila, M. Wischmeier, H.W. Müller, et al., Outer divertor of ASDEX Upgrade in low-density L-mode discharges in forward and reversed magnetic field: I. Comparison 
between measured plasma conditions and SOLPS5.0 code calculations, Nucl. Fusion 52, 103006 (2012), http://dx.doi.org/10.1088/0029-5515/52/10/103006

[31] S.W. Lisgo, A. Kukushkin, R.A. Pitts, et al., Design assessment of tungsten as an upper panel plasma facing material in ITER, J. Nucl. Mater. 438, S580 (2013), http://dx.doi. org/10.1016/j.jnucmat.2013.01.121

[32] J.D. Elder, P.C. Stangeby, D.G. Whyte, et al., OEDGE modeling of 13C deposition in the inner divertor of DIII-D, J. Nucl. Mater. 337, 79 (2005), http://dx.doi.org/10.1016/ j.jnucmat.2004.10.138

[33] A. Xuereb, M. Groth, K. Krieger, et al., DIVIMP-B2-EIRENE modelling of 13C migration and deposition in ASDEX Upgrade L-mode plasmas, J. Nucl. Mater. 396, 228 (2010), http://dx.doi.org/10.1016/j.jnucmat.2009.11.014

[34] M.W. Thompson, II. The energy spectrum of ejected atoms during the high energy sputtering of gold, Philos. Mag. 18, 377 (1968), http://dx.doi.org/10.1080/ 14786436808227358

[35] R.M. McDermott, C. Angioni, R. Dux, et al., Effect of electron cyclotron resonance heating (ECRH) on toroidal rotation in ASDEX Upgrade H-mode discharges, Plasma Phys. Control. Fusion 53, 035007 (2011), http://dx.doi.org/10.1088/0741-3335/53/3/035007

[36] M. Mayer, V. Rohde, K. Sugiyama, et al., Carbon balance and deuterium inventory from a carbon dominated to a full tungsten ASDEX Upgrade, J. Nucl. Mater. 390, 538 (2009), http://dx.doi.org/10.1016/j.jnucmat.2009.01.087

[37] M. Oberkofler, G. Meisl, A. Hakola, et al., Nitrogen retention mechanisms in tokamaks with beryllium and tungsten plasma-facing surfaces, Submitted to Phys. Scr. (2015)

[38] S. Droste, A. Kirschner, D. Borodin, et al., Modelling of 13CH4 injection experiments with graphite and tungsten test limiters in TEXTOR using the coupled code ERO- 
SDTrimSP, Plasma Phys. Control. Fusion 50, 0150062008, http://dx.doi.org/10. $1088 / 0741-3335 / 50 / 1 / 015006$

[39] W. Möller, W. Eckstein, and J.P. Biersack, Tridyn-binary collision simulation of atomic collisions and dynamic composition changes in solids, Comp. Phys. Comm. 51, 355 (1988), http://dx.doi.org/10.1016/0010-4655(88)90148-8

[40] A. Mutzke, R. Schneider, W. Eckstein, and R. Dohmen, SDTrimSP Version 5.00, IPP Report 12/08, Max-Planck-Institut für Plasmaphysik (Hrsg.) (2011), http://edoc.mpg. de/display $\cdot$ epl?mode=doc\&id=552734\&col=33\&grp=1311\#cb

[41] K. Schmid, M. Mayer, C. Adelhelm, et al., Impact of gyro-motion and sheath acceleration on the flux distribution on rough surfaces, Nucl. Fusion 50, 105004 (2010), http://dx. doi.org/10.1088/0029-5515/50/10/105004

[42] D. Naujoks, R. Behrisch, J.P. Coad and L.C.J.M. De Kock, Material transport by erosion and redeposition on surface probes in the scrape-off layer of JET, Nucl. Fusion 33, 581 (1993), http://dx.doi.org/10.1088/0029-5515/33/4/I05

[43] J. Miettunen, M.I. Airila, T. Makkonen, et al., Dissociation of methane and nitrogen molecules and global transport of tracer impurities in an ASDEX Upgrade L-mode plasma, Plasma Phys. Control. Fusion 56, 095029 (2014), http://dx.doi.org/10.1088/ 0741-3335/56/9/095029

[44] P.C. Stangeby, The Plasma Boundary of Magnetic Fusion Devices, Institute of Physics Publishing, Bristol and Philadelphia, 2000.

[45] G. Meisl, K. Schmid, K. Krieger, et al., Simulating the nitrogen migration in Be/W tokamaks with WallDYN, Submitted to Phys. Scr. (2015) 
$N$ Flux from surface $\left(10^{20} \mathrm{~m}^{-2} \mathrm{~s}^{-1}\right)$
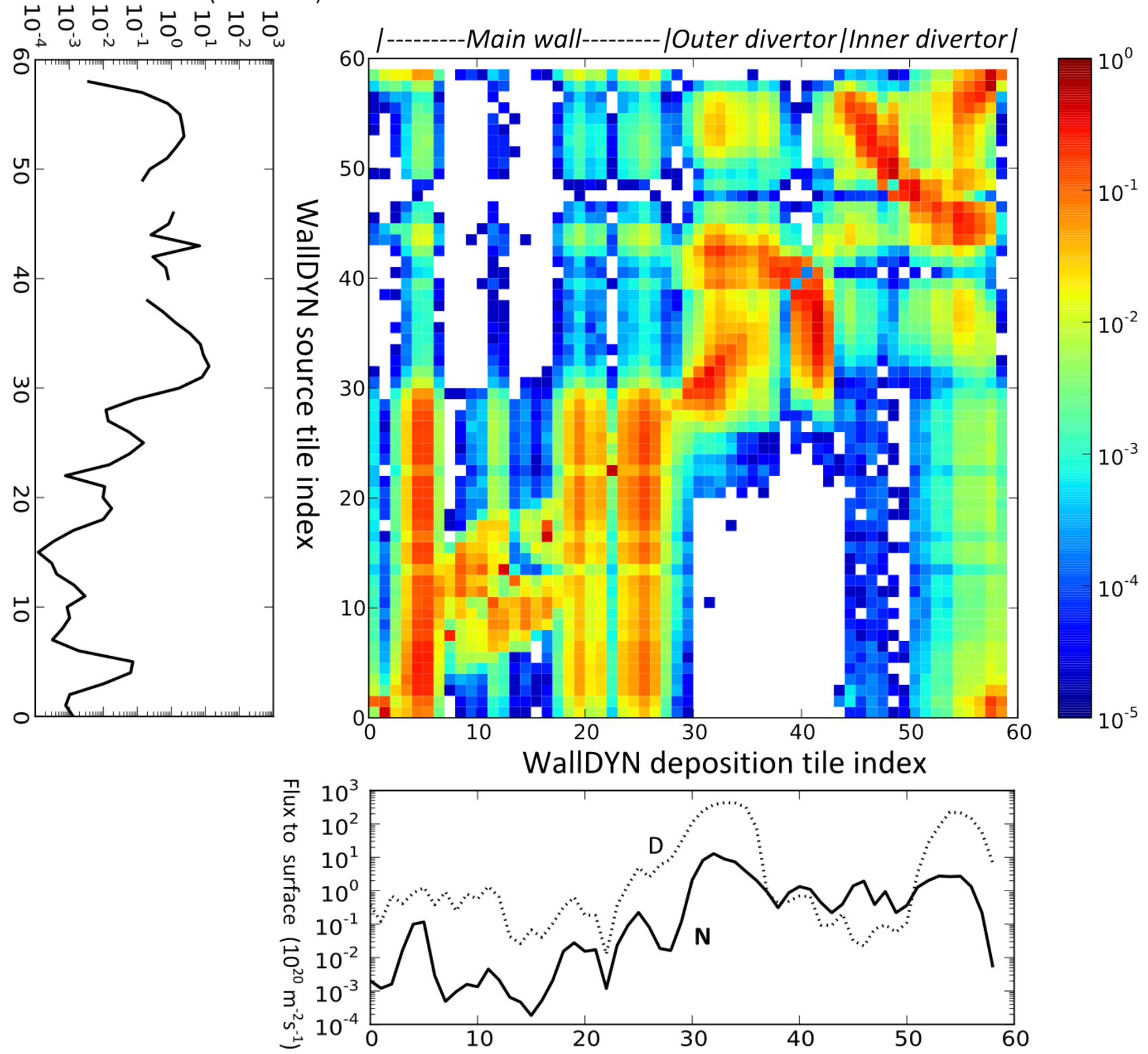

Figure 16: Charge state integrated nitrogen re-distribution matrix calculated with the low $T_{e} S O L P S$ plasma background. The figures to the left and at the bottom show the $N$ fluxes from the WallDYN simulation at $t=2.3 \mathrm{~s}$ (corresponding to the end of the first $N$-seeded phase). The $N$ fluxes are calculated by solving the self-consistent equation for the impurity fluxes, which includes the information from the re-distribution matrix. The figure at the bottom also contains the D flux taken from SOLPS (and the OSM solution in the extended grid region) for reference. 


\section{A Nitrogen re-distribution matrix}

Fig. 16 shows the charge state integrated nitrogen re-distribution matrix calculated with the low $T_{e}$ plasma background with extended grid. The transport of the impurities through the plasma is parameterized for WallDYN by such re-distribution matrices calculated with DIVIMP. A redistribution matrix states which percentage of the material eroded from a given tile impinges on another tile. Diagonal contributions indicate local re-deposition. $\mathrm{N}$ from the puff region (tile 44) mainly goes to the outer and inner divertor. Material from the main wall is deposited in the inner divertor but not in the outer divertor (source tile indices 0-25 have no contribution to deposition on tiles 30-40). The sum of each line is one, reflecting the particle conservation. 